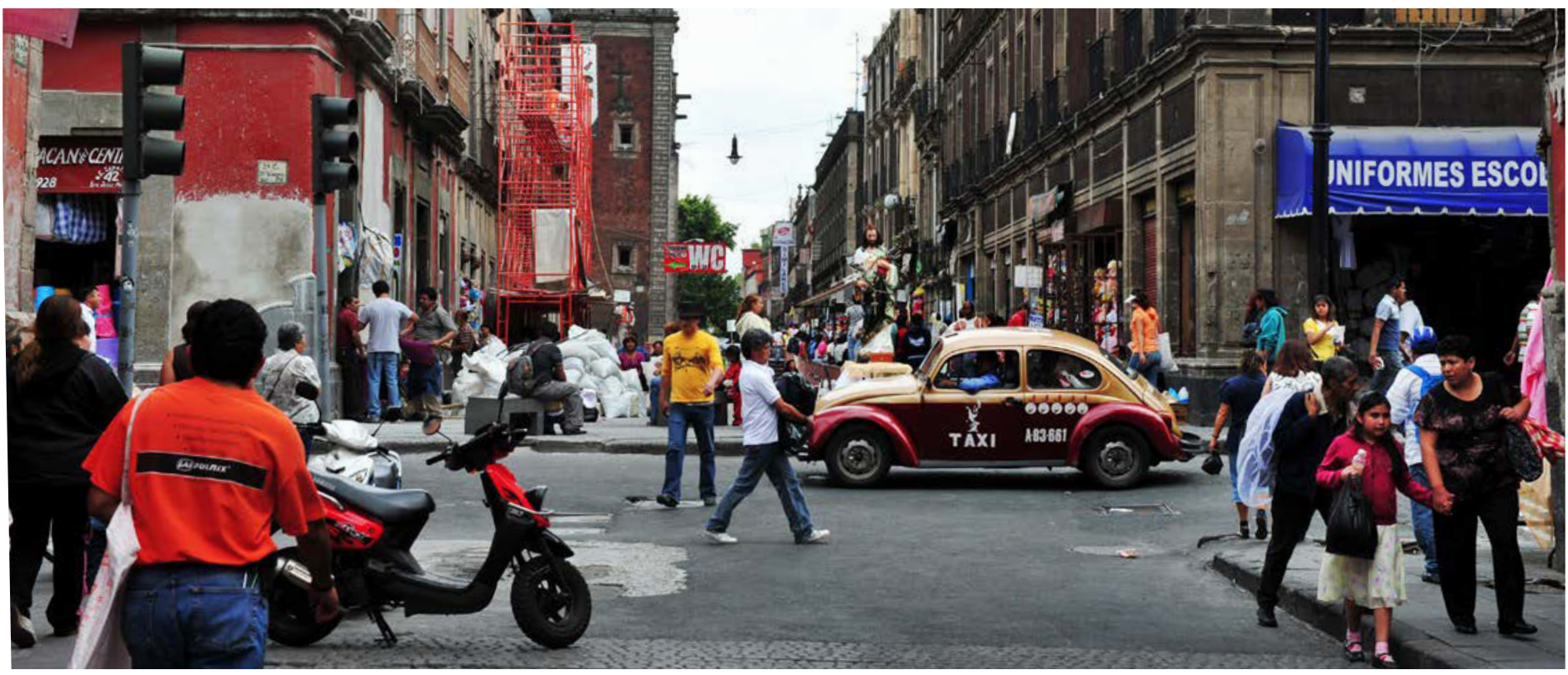

Mexico City, Mexico - Photo from iStock 542819328

\title{
The Value of Motorcycle Electrification in Mexico City
}

\section{Background}

Local and city governments worldwide are looking to adopt emerging technologies and mobility approaches, such as electric vehicles, as they pursue their environmental and economic goals. Commercially available electric vehicles include buses, automobiles, motorcycles, and other two-wheelers. Electrifying transportation is critical to achieve urban sustainability, but it also raises challenges for private and public actors. Jurisdictions across countries are seeking to answer big questions, including how the transportation sector can be electrified, what impacts are priorities, and how such impacts can be obtained.

Electric vehicles produce zero tailpipe emissions (e.g. carbon dioxide, carbon monoxide, particulate matter) and therefore can reduce transportation-related air pollution in urban areas compared to conventional vehicles. The generation of electricity to power electric vehicles is another source of emissions; the electricity mix where the vehicle is charged determines the type and quantity of these. A renewable energy-based electricity mix will allow driving an electric vehicle to result in even fewer emissions than a conventional vehicle (McLaren et al. 2016); however, regardless of the electricity mix used to charge an electric vehicle, overall electric vehicle emissions are less than conventional vehicles (McLaren et al. 2016). In Europe, for instance, electric vehicles have 17\%-30\% lower greenhouse gas emissions than conventional vehicles over the entire life cycle of the vehicle, and this difference is expected to increase as Europe's energy mix decreases in carbon intensity (more renewable energy generation, less fossil fuel generation) (EEA 2018).
Electric vehicles typically have lower fuel costs than conventional vehicles; however, initial costs of electric vehicles are higher than for conventional vehicles. The creation and maintenance of public electric vehicle charging stations is an additional challenge for cities, as is transforming public transportation fleets to run on electricity. Switching from a conventional public transportation bus fleet to battery electric buses is initially expensive, as battery electric buses cost more than conventional buses. Charging electric bus fleets also presents challenges, such as where to locate charging stations and how to evaluate their impacts on electric grids. Over time and with optimal operation, however, battery electric buses can provide cost savings in the long run in lower fuel expenses and avoided maintenance costs (Casale and Mahoney 2018). 
The global market for motorcycles (and other two-wheelers, including mopeds and scooters) is growing rapidly. Electric two-wheelers made up 30\% of the global two-wheeler sales in 2019. In 2033, 50\% of global two-wheeler sales are expected to be electric. Growth in electric two-wheeler sales is driven by government policies, rising gross domestic product (GDP) per capita, urbanization, and population growth. In addition, electric two-wheelers are cheaper in terms of total cost of ownership than conventional two wheelers (BNEF 2020).

Jurisdictions trying to electrify their transportation systems and understand the resulting impacts are seeking to answer many questions. The case study that follows details one jurisdiction's approach to answering some of these questions.

- How does transportation electrification impact air quality?

- How does transportation electrification affect mobility?

- Which strategies best facilitate rapid, cost-effective, and equitable progress toward transportation electrification? What are the pros and cons of these strategies?

- What roles do public and private entities play in mobility electrification?

- How does increased mobility electrification affect utilities and the broader power sector?

\section{Mexico City Vehicle Electrification Study}

\section{Mexico City Transportation}

In 1992, the United Nations declared that Mexico City was the most polluted city in the world (C40 Cities). Though the city has taken steps to improve air quality since that report, the city still suffers from consistently high levels of air pollutants, including ozone, carbon monoxide, sulfur dioxide, and nitrogen dioxide as well as air pollution emergencies.
Mobility access is also an issue in Mexico City. The city consistently ranks as one of the most congested cities in the world. In addition, 5.5 million people use the public transportation system daily, though it is only designed to serve 4.5 million (Flannery 2019). Inequality of mobility access is prevalent in Mexico City, as the outskirts of the city have limited public transit services. This is why the peripheries of the city rely on mototaxis (a cart bike or bike taxi) and the pesero system (decentralized microbus system of transportation).

The challenges that Mexico City faces in its transportation sector, from congestion to dangerous emissions, prompted the city's leaders to seek solutions. Through a series of meetings in February 2019 with Mexico City's Minister of Mobility and Minister of the Environment, NREL researchers found that progress toward improved air quality and mobility access was a major priority among city officials. Electrification of commercial motorcycles, including mototaxis and motodelivery (i.e., Rappi and Uber Eats) vehicles, was highlighted by city officials as a potential area of opportunity for electrification. The team convened two focus groups on electrification of transportation in Mexico City and conducted a technical analysis on the potential benefits of motorcycle electrification.

\section{Focus Groups}

The focus groups gauged private and governmental actors' understandings of the options and barriers to the electrification of transportation in Mexico City. All participants in both focus groups believed that the success of the transition to electric mobility depends not only on technological innovations driven by the vehicle industry, but also on policies implemented by the federal government. Furthermore, they see this as an opportunity to reduce emissions and improve mobility in the city.

The focus group meetings determined that electrification of first and last mile transportation of people and goods as an area of opportunity for progress towards the mobility and air quality goals of stakeholders. The electrification of commercial motorcycles was highlighted by these groups as an area of interest.

\section{Why Electrified Motorcycles?}

Number of Motorcycles: Motorcycle registrations in Mexico City are increasing rapidly, and they are a popular mode choice for first/last mile transport of people and goods.

Air Pollutants: Gasoline-powered motorcycles emit air pollutants at a significantly higher rate than automobiles while

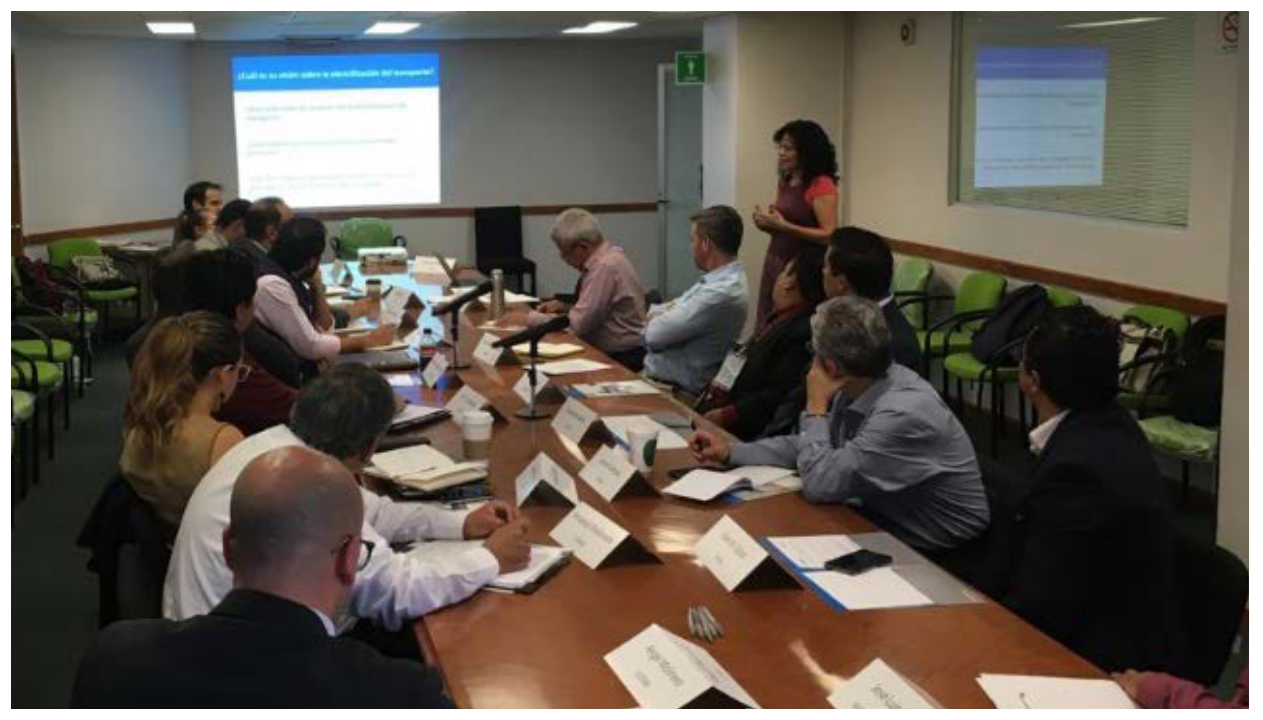

Figure 1. Focus group in Mexico City, 2019 - Photo by Caro Neri, 2019 
carrying fewer passengers on average. Therefore, electrifying one motorcycle has a proportionally larger air quality benefit than electrifying one automobile. Figure 2 illustrates the difference in air pollutant emissions between motorcycles and automobiles. Lower occupancy and higher emissions make motorcycles an area of opportunity for air quality and greenhouse gas improvements.

Equitability: Mototaxis are heavily used in the periphery of Mexico City. Electrification could promote better air quality and provide more equitable access to economic and transit hubs in these often less dense, yet highly populated areas.

\section{High Vehicle-Kilometers Traveled}

(VKT): Emissions and energy reductions are directly proportional to the percentage of VKT electrified. The greatest emissions reductions for the lowest cost will come from electrification of high-VKT vehicles, which are mototaxis and motodelivery vehicles. In Mexico City, personal motorcycles travel approximately $13.6 \mathrm{~km} /$ day, while mototaxis and motodelivery vehicles travel at least $20 \mathrm{~km} /$ day on average, according to survey data. ${ }^{1}$

\section{Quantifying the Benefits of Electric Motorcycles}

The technical analysis sought to explore potential emissions and mobility benefits realized from various motorcycle electrification scenarios.

Motorcycles have lower occupancy than buses or automobiles and therefore each motorcycle trip may result in more emissions per kilometer than a car trip. Figure 3 demonstrates emissions reductions (emissions from motorcycle and car combined) through electrification of motorcycle kilometers. Scenarios electrifying $0 \%$ (business as usual), $25 \%$, and $50 \%$ of motorcycle kilometers traveled are shown. Though motorcycles only make up $2 \%$ of trips in Mexico City, partial electrification of motorcycles could result in reductions in pollutants by $10-20 \%$.

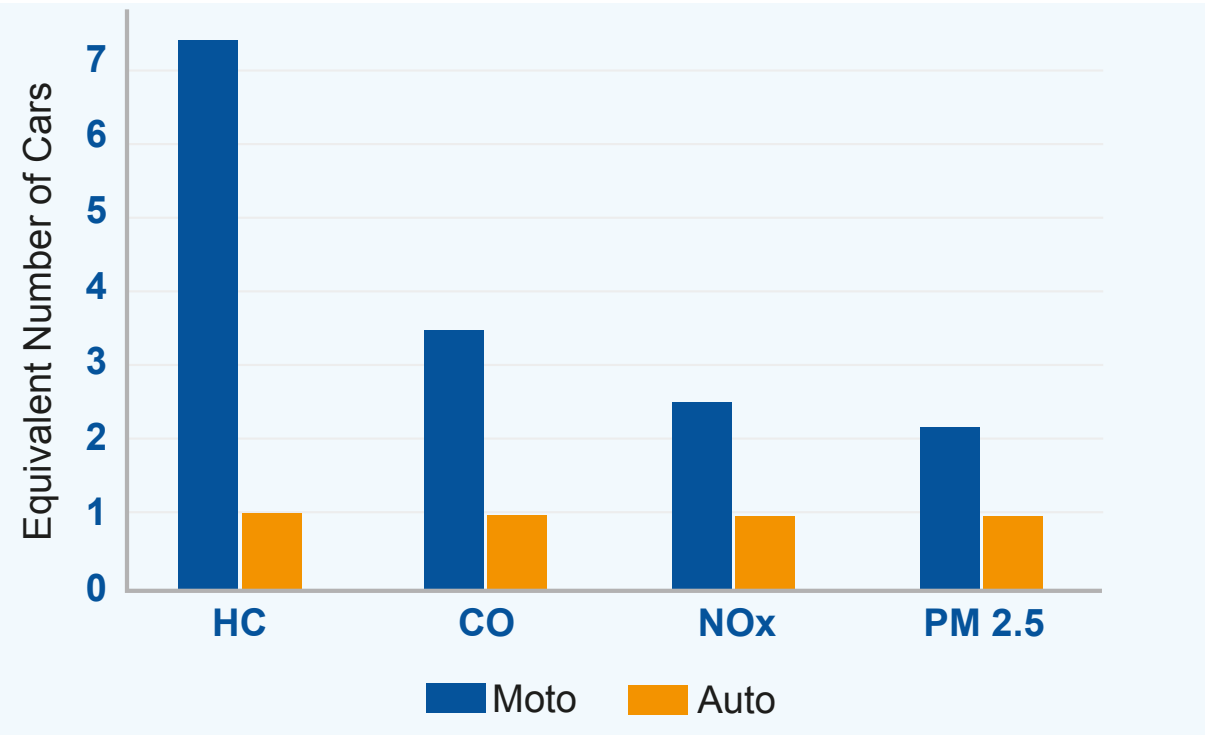

Figure 2: Comparison of the amount of emissions (CO: Carbon monoxide, HC: Hydrocarbon, NOx: Nitrogen oxides, PM 2.5: Particulate Matter 2.5) that occur for one motorcycle driving the same distance as one car.

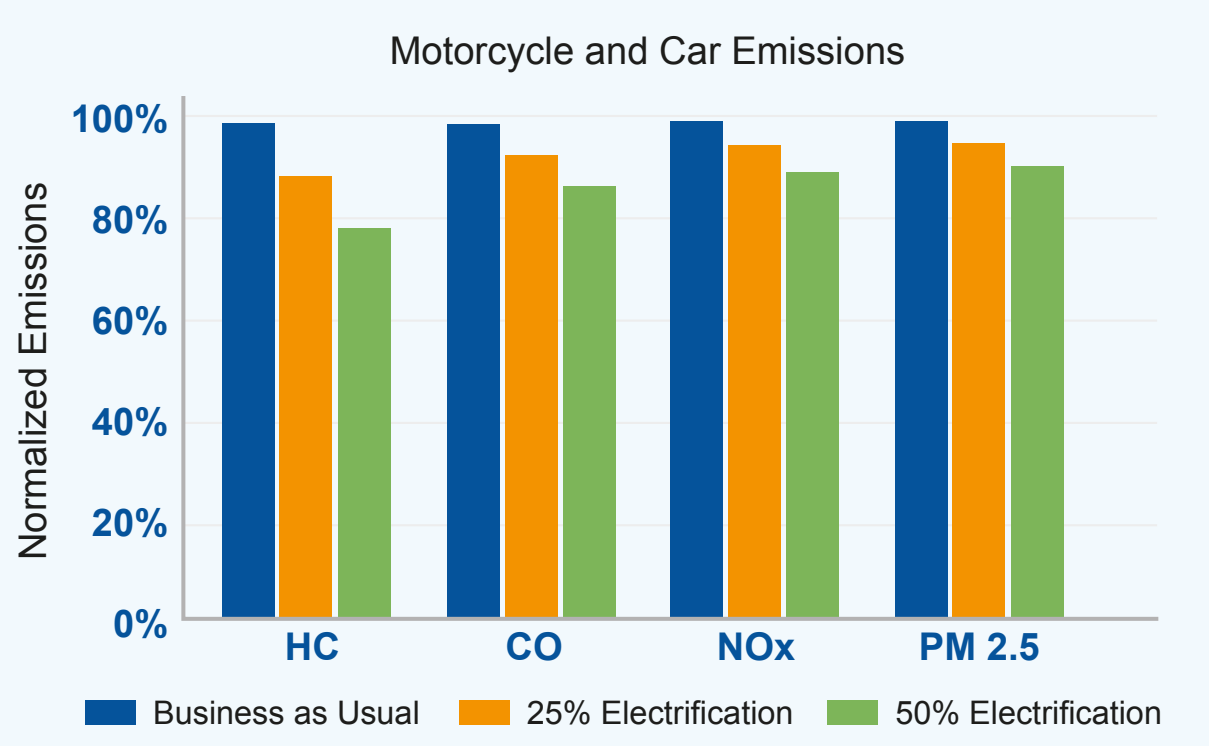

Figure 3. Normalized emissions benefits from motorcycles and cars in Mexico City for cases with $0 \%, 25 \%$, and $50 \%$ electric motorcycle kilometers electrification (CO: Carbon monoxide, HC: Hydrocarbon, NOx: Nitrogen oxides, PM 2.5: Particulate Matter 2.5)

The highest daily kilometers travelled per person (for all vehicle types) was observed in districts in the periphery of Mexico City, where focus group participants noted that motorcycle usage is higher than average. Given that the amount of motorcycles in service as taxis and food delivery vehicles is growing rapidly, especially in areas where people are, on average, traveling the most, near-term electrification of these vehicles could support improvements in air quality in Mexico City with minimal required investment. 


\section{Conclusions}

An emphasis on automobile and truck electrification is crucial to achieving environmental goals in Mexico City because motorcycles are a proportionally small share of overall gasoline and diesel consumption. However, the number of motorcycles used for commercial applications is growing. Commercial motorcycles present an opportunity for substantial emissions reductions as well as mobility access and equity benefits in Mexico City.

\section{Further Reading}

Greening the Grid: Mexico: https:// greeningthegrid.org/where-we-work/ greening-the-grid-mexico

National Renewable Energy Vehicle Technology Integration: https://www.nrel. gov/transportation/vehicle-technology-integration.html

United States Department of Energy Alternative Fuels Data Center: https:// afdc.energy.gov/

United States Department of Energy Electric Vehicle Infrastructure Project Tool (EVI-Pro) Lite: https://afdc.energy.gov/ evi-pro-lite

\section{Acknowledgments}

Madeline Gilleran, Jacob Holden, Patricia Romero Lankao, Andrea Watson, Dustin Weigl, NREL; Caro Neri, RASEI.

\section{References}

BloombergNEF. “How Fast Will Two-Wheelers Electrify?” April 16, 2020. https://www.bnef.com/insights/22689/view.

Casale, Matt, and Brendan Mahoney. "Paying for Electric Buses." U.S. PIRG Education Fund, 2018.

https://uspirg.org/sites/pirg/files/reports/National\%20-\%20Paying\%20for\%20 Electric $\% 20$ Buses.pdf.

C40 Cities. “Mexico City: ProAire.” Accessed April 20, 2020.

https://www.c40.org/profiles/2013- mexicocity.

European Environment Agency. "EEA Report Confirms: Electric Cars Are Better for Climate and Air Quality.” News. November 22, 2018.

https://www.eea.europa.eu/highlights/eea-report-confirms-electric-cars.

Flannery, Nathaniel Parish. "Mexico City Needs To Address Its Urban Mobility Problems.” Forbes. June 27, 2019.

https://www.forbes.com/sites/nathanielparishflannery/2019/06/27/ mexico-city-needs-to-address-its-urban-mobility-problems/.

McLaren, Joyce, John Miller, Eric O’Shaughnessy, Eric Wood, and Evan Shapiro. Emissions Associated with Electric Vehicle Charging: Impact of Electricity Generation Mix, Charging Infrastructure Availability, and Vehicle Type. Golden, CO: National Renewable Energy Laboratory. NREL/TP-6A20-64852. April 2016. https://doi.org/10.2172/1247645.

Written by Laura Beshilas and Alexandra Aznar, National Renewable Energy Laboratory

\section{www.greeningthegrid.org | www.nrel.gov/usaid-partnership}

This work was authored, in part, by the National Renewable Energy Laboratory (NREL), operated by Alliance for Sustainable Energy, LLC, for the U.S. Department of Energy (DOE) under Contract No. DE-AC36-08GO28308. Funding provided by the United States Agency for International Development (USAID) under Contract No. IAG-17-2050. The views expressed in this report do not necessarily represent the views of the DOE or the U.S. Government, or any agency thereof, including USAID.

Greening the Grid is a platform for expertly curated information, tools, and technical assistance to support countries in power system transformation and grid modernization. Greening the Grid is supported by the U.S. Agency for International Development.

The USAID-NREL Partnership addresses critical challenges to scaling up advanced energy systems through global tools and technical assistance, including the Renewable Energy Data Explorer, Greening the Grid, the International Jobs and Economic Development Impacts tool, and the Resilient Energy Platform. More information can be found at: www.nrel.gov/usaid-partnership.

USAID

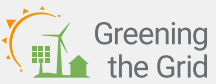

INREL

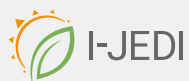

Resilient Energy 